\title{
Stress Analysis of Rib-to-Deck Joints in Orthotropic Steel Deck Based on Nominal and Effective Notch Stress Approaches
}

\author{
Piya Chotickai ${ }^{\mathrm{a},}$ and Thongsoi Srisawat ${ }^{\mathrm{b}}$ \\ Department of Civil Engineering, Kasetsart University, 50 Ngam Wong Wan Rd., Lat Yao, Chatuchak, \\ Bangkok 10900, Thailand \\ E-mail: a,*fengpyc@ku.ac.th (Corresponding author), bthongsoi_srisawat@hotmail.com
}

\begin{abstract}
This paper presents the stress analysis of the rib-to-deck (RD) joint in an orthotropic steel deck. Finite element models were developed to evaluate the effects of the wheel load location and weld penetration ratio on the nominal and effective notch stres ses at the RD joint. The critical wheel load locations for fatigue-sensitive locations of the RD joint were investigated comprehensively. The potential locations of fatigue crack initiation were evaluated for weld penetration ratios ranging from $0 \%$ to $100 \%$ at different transverse locations of single- and double-wheel loads. The analytical results indicated that the critical location of fatigue crack initiation was influenced by the weld penetration ratio and transverse wheel load location. An increase in the weld penetration ratio decreased the root notch stress and significantly increased the potential for toe-deck cracking, as the wheel loads were applied at the RD joint and close to the adjacent rib. The nominal stress approach was used to identify the fatigue crack type accurately only for relatively high weld penetration ratios, with the wheel loads applied at the RD joint and over the rib. For the condition of $100 \%$ weld penetration ratio with the loads applied at the joint, the fatigue life corresponding to the effective notch stress approach ranged from $66 \%$ to $73 \%$ of the fatigue life obtained using the nominal stress approach.
\end{abstract}

Keywords: Fatigue, finite element, nominal stress, effective notch stress, orthotropic, ribto-deck joint, steel.

ENGINEERING JOURNAL Volume 25 Issue 7

Received 10 October 2020

Accepted 1 July 2021

Published 31 July 2021

Online at https://engj.org/

DOI:10.4186/ej.2021.25.7.17 


\section{Introduction}

Orthotropic steel decks are widely used in long-span bridges owing to their low self-weight, high load-carrying capacity, and ease of construction. The deck plate is supported by a series of open or closed longitudinal ribs that span between transverse cross girders or floor beams. The closed-rib type is generally used in decks with wide diaphragm spacing because of its higher torsional and flexural stiffness [1]. Closed rib-to-deck (RD) joints are commonly fabricated using fillet welds with a certain degree of weld penetration [2,3]. The orthotropic deck is subjected to out-of-plane flexural stresses from traffic loads owing to its relatively slender elements and is susceptible to fatigue damage.

Fatigue resistance at the rib-to-deck joint has been experimentally and analytically investigated in previous studies [4-8]. Four types of fatigue cracks, i.e., toe-deck, toe-rib, root-deck, and weld root cracks, occur at RD joints in orthotropic decks. In the toe-deck and toe-rib types, fatigue cracks are initiated at the weld toe and subsequently, propagate into the deck or rib. Conversely, in the root-deck and weld root types, fatigue cracks originate at the weld root and propagate into the deck or weld throat. The weld root crack can be prevented through adequate weld penetration [9]. A weld penetration ratio of $80 \%$ of the rib wall thickness is recommended in the AASHTO load and resistance factor design (LRFD) specifications [10]. An adequate thickness of the rib wall behind the weld root is required to prevent the occurrence of weld defects called "weld melt-through" [11]. Based on the nominal stress approach, the AASHTO LRFD specifications provide the fatigue resistance of toe-decks and toe-ribs for $70 \%$ $80 \%$ weld penetration ratios as AASHTO Class C. In addition, the International Institute of Welding (IIW) guidelines [12] provide the fatigue resistance based on the nominal stress approach at the weld toe and weld root for $100 \%$ penetration ratio and the weld throat for $0 \%$ and partial penetration ratios as FAT 71 .

Given the existence of tensile residual stress, the fatigue cracks that originate from the joint depend on both the tensile stress and stress range, although crack propagation is primarily influenced by the tensile stress [13]. The residual stress on the deck surface along the weld line exists in tension. The value of the residual stress is comparable with the yielding stress value, and it increases with weld penetration $[14,15]$. Fu et al. [8] experimentally investigated the fatigue resistance of $\mathrm{RD}$ joints subjected to fully reversed bending using a mechanical vibration fatigue test machine for $80 \%$ and $100 \%$ penetration ratios. An increase in the penetration ratio from $80 \%$ to $100 \%$ decreased the crack propagation rate and increased the fatigue life. Most of the fatigue cracks occurred at weld root and propagated into the deck. Kainuma et al. [16] evaluated the fatigue resistance of $\mathrm{RD}$ joints for various penetration ratios ranging from $0 \%$ to $100 \%$ of full-scale orthotropic steel decks under single- and double-loading conditions applied over a rib wall. Three types of fatigue damage - root cracking only, both toe and root cracking, and non-crack initiationwere observed. An increase in the penetration ratio decreased the crack depth and crack length and prevented root cracking. Li et al. [9] assessed the fatigue resistance of RD joints for $15 \%$ and $75 \%$ penetration ratios subjected to an applied load on the adjacent rib wall. The joints for the $15 \%$ and $75 \%$ penetration ratios were fractured by weld root and toe-deck cracks, respectively, and an increase in the penetration ratio prevented the formation of weld root cracks. Ya et al. [2] investigated and compared the fatigue resistance of $\mathrm{RD}$ joints that experienced weld melt-through with that of $80 \%$ penetration ratio. The RD joints were subjected to bending using a mechanical vibration fatigue test machine at a stress ratio of 0.2 . The weld melt-through influenced the formation of fatigue cracks and slightly decreased fatigue resistance. Owing to the scatter of the fatigue test results, the fatigue resistance of the $\mathrm{RD}$ joints for different penetration ratios could be reasonably estimated as AASHTO Class C. Sim and Uang [5] researched on the effect of the weld penetration ratio $(40 \%, 60 \%$, and $80 \%)$ on the local stresses at the weld toe and weld root using an effective notch stress approach. The penetration ratio was found to have an insignificant effect on the local stress at the weld toe; however, the root notch stress increased with the penetration ratio. Wang et al. [17] experimentally and analytically investigated the crack initiation location and crack propagation path of the RD joints and accurately predicted the crack propagation path using an effective notch stress approach. The fatigue resistance of the RD joints was rationally assessed using the fatigue resistance curve recommended by the IIW [18]. Recently, the fatigue resistance of the $\mathrm{RD}$ joint with a thickened-edge U-rib was investigated by Luo et al. [19]. An increase in the edge thickness of the rib wall did not significantly increase the fatigue resistance when compared with the conventional rib joint. The effective notch stress was more effective than the nominal stress in predicting the fatigue crack type.

A few studies on the structural responses of the orthotropic decks under vehicle loads have been investigated, despite the complex structural behavior of orthotropic decks [20-22]. The stress responses at the $\mathrm{RD}$ joint are dominated by concentrated wheel loads and depend on the geometrical characteristics and relative slenderness of the elements at the joint [23]. The peak stress response at the joint is obtained based on each wheel load. Because of the localized characteristics and the variation in wheel load locations, the number of stress cycles induced by each vehicle passage can vary significantly. The AASHTO LRFD code [10] specifies a five-axle fatigue truck for computing the primary stress range and fatigue damage of $\mathrm{RD}$ joints. The fatigue truck comprises a $35.6 \mathrm{kN}$ single axle and two $142.3 \mathrm{kN}$ double axles. The axle configurations represent a five-axle singletrailer truck. Xiao et al. [24] analyzed the effects of double-wheel-load locations on fatigue damage at the RD 
joint of trapezoidal ribs. The out-of-plane bending stress dominated the transverse stresses at the joint. Concerning three different wheel load locations (over-rib, in-between-ribs, and riding-rib-wall), the transverse stresses in the deck plate significantly exceeded those in the rib wall, and fatigue cracking was prone to commence from the toe-deck or root-deck. Zhou et al. [25] evaluated the effective stress ranges for fatigue occurrence at the $\mathrm{RD}$ joint using transverse in-lane location data collected from a weigh-in-motion system and influence lines plotted via finite element analysis. The transverse wheel load distribution was found to influence the fatigue damage at the joint significantly and was recommended for inclusion in the calculation process.

In summary, several studies on the effect of the weld penetration ratio on the fatigue resistance and fatigue crack type of the RD joint have been conducted. However, the configuration and location of applied loads considered in the studies were limited to certain types and may not represent the actual variation in loading patterns of the RD joint in bridges. Therefore, the effects of load location and configuration on the stress responses and critical location for fatigue crack initiation at the RD joint for different weld penetration ratios should be investigated to evaluate the fatigue damage and fatigue crack initiation of the RD joint comprehensively. The aim of this study is to evaluate the structural responses and fatigue crack type of the $\mathrm{RD}$ joint at various wheel load locations and for different configurations. Global and sub-finite element models were developed to evaluate the nominal and effective notch stresses at fatigue-sensitive locations in the RD joint. The critical locations for fatigue damage corresponding to single- and double-wheel loads were determined. The effects of the location and configuration of the wheel load on the crack initiation location were evaluated for weld penetration ratios ranging from $0 \%$ to $100 \%$. Finally, the fatigue life corresponding to the wheel loads of the AASHTO fatigue truck determined using the nominal and effective notch stress approaches were evaluated and compared.

\section{Structural Description}

In this study, the orthotropic deck was a part of a single-plane fan-type cable-stayed bridge with an overall span length of $782 \mathrm{~m}$ and six traffic lanes. The main span of the bridge corresponded to a trapezoidal-shaped steel box girder (Fig. 1a) with an overall height of approximately $4 \mathrm{~m}$ and width of $33 \mathrm{~m}$ at the deck level. Two vertical longitudinal diaphragms were continuously provided along the length of the bridge. At each crossgirder section, four diagonal steel tubes that formed a $\mathrm{K}$ frame were provided to transfer loads between the top and bottom cross girders. The wearing surface was composed of a $75 \mathrm{~mm}$ thick bituminous material.

The bridge deck consisted of an orthotropic steel plate of $12 \mathrm{~mm}$ thickness stiffened with closed trapezoidal-shaped longitudinal ribs of $8 \mathrm{~mm}$ thickness spanning across $3600 \mathrm{~mm}$ spacing cross girders. The top width, bottom width, and height of the longitudinal ribs were 300, 200, and $275 \mathrm{~mm}$, respectively. The spacing between two successive longitudinal ribs was $300 \mathrm{~mm}$. Fig. 1(b) shows a typical cross-section of the orthotropic steel deck.

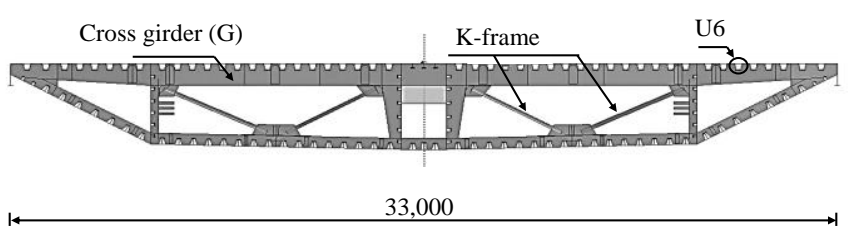

a) Bridge cross-section

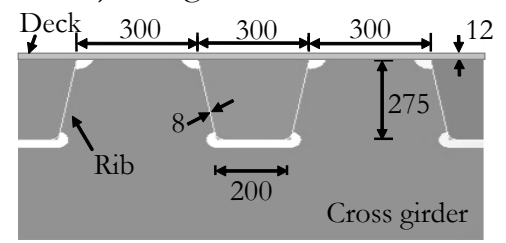

b) Dimension of closed ribs

Fig. 1. Bridge cross-section and configurations of closed ribs (Dimensions in $\mathrm{mm}$ ).

\section{Finite Element Model}

Finite element analysis was performed to investigate the stress responses at fatigue-sensitive locations, including the toe-deck, root-deck, weld-throat, and toerib, for various transverse and longitudinal wheel load locations. Global and sub-finite element models were developed to evaluate the stress responses based on the nominal and effective notch stress approaches. The stress responses were used in conjunction with the fatigue resistance curves recommended by the IIW $[12,18]$. These curves were developed with inclusion of the residual stress effect at the welded joints. Thus, the residual stress was excluded in the finite element analysis in this study. The critical locations and stress responses for the single- and double-wheel loads were analyzed at the midspan between cross girders. The influence lines of the stress ranges of the U6 rib were plotted (Fig. 1(a)). The U6 rib was located along the centerline of wheel loads in the outer lane, and this lane was subjected to numerous cycles of truck traffic loading.

\subsection{Global Finite Element Model}

A global finite element model was developed for a portion of the orthotropic steel deck using ANSYS software. The model consisted of 10 ribs and seven cross beams with an overall dimension of $10.2 \mathrm{~m} \times 21.7 \mathrm{~m}$ (Fig. 2). A shell element (SHELL 181) with six degrees of freedom per node was used to represent the rib, floor beam, and deck plate. The sizes of elements at locations away from the RD joint ranged from 25 to $100 \mathrm{~mm}$. Fine meshes with element sizes of 5 and $25 \mathrm{~mm}$ were used in a region close to the $\mathrm{RD}$ joint (Fig. 3) and under the wheel-loading area, respectively. The structural responses 
at Joint A, located at the midspan and represented a typical RD joint, was investigated.

Boundary conditions were applied to approximate the structural responses at the $\mathrm{RD}$ joint under wheel loads. Considering the local effect of wheel loads on the stress responses at the $\mathrm{RD}$ joint, the partial representation of the orthotropic deck was applied to provide a reasonable estimate of the structural responses at the joint. Translations in the $\mathrm{Y}$ - and Z-directions were constrained along two longitudinal deck edges (LD) to model the continuity in deck and ribs, and translation in the $\mathrm{X}$-direction and rotation about the $\mathrm{Y}$-axis were constrained along two transverse edges (TD). Translations in the $\mathrm{X}$-, $\mathrm{Y}$-, and Z-directions were constrained on 14 end edges of the cross girders (CGs) to model the continuity of the CGs and vertical diaphragm (VD), and translations in the $\mathrm{Y}$ - and $\mathrm{Z}$ directions were constrained for all the nodes along the bottom edge of the VD. In addition, translations in the $\mathrm{Y}$ - and Z-directions were constrained at the $\mathrm{K}$-frame joint connection $(\mathrm{KF})$.



Fig. 2. Global finite element model.
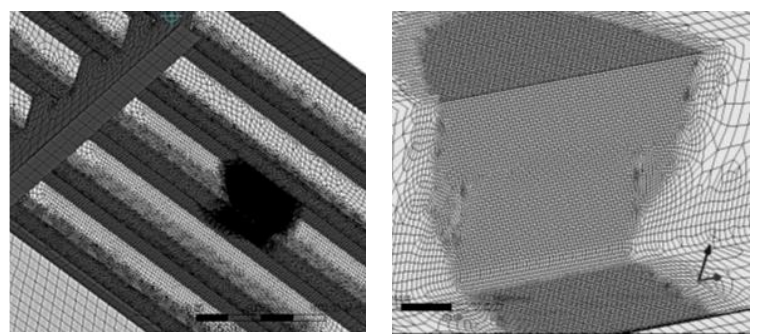

Fig. 3. Mesh at Joint A in global finite element model.

The wheel load was assumed to be uniformly distributed over the tire contact area of $200 \mathrm{~mm} \times 200$ $\mathrm{mm}$ for a single wheel and $500 \mathrm{~mm} \times 200 \mathrm{~mm}$ for double wheels based on BS 5400-10 [26]. Pressure from the tire contact was distributed on the deck at $45^{\circ}$ through the $75 \mathrm{~mm}$ thick wearing surface and resulted in a loading area of $350 \mathrm{~mm} \times 350 \mathrm{~mm}$ and $650 \mathrm{~mm} \times 350$ $\mathrm{mm}$ on the steel deck for the single and double wheels, respectively. The deck deformations and the influence lines of stress responses at Joint A under $1 \mathrm{kN}$ singleand double-wheel loads at various transverse and longitudinal locations were analyzed.

\subsection{Sub-Finite Element Model}

Two levels of sub-finite element models were developed for the RD joint. The large first level of the sub-models contained one span $(3600 \mathrm{~mm})$ between CGs of the orthotropic steel deck and five ribs (Fig. 4a). Four large sub-models were established for penetration ratios of $0 \%, 50 \%, 80 \%$, and $100 \%$, which were denoted as Models S-0, S-50, S-80, and S-100, respectively, with a one-side $6 \mathrm{~mm}$ fillet weld. The models were developed using 20-node solid elements with a quadratic displacement function (SOLID 186). The boundary conditions of the sub-models were constrained by the displacement of the global model using the cut boundary condition method, and the models were used to apply the boundary conditions for the small second level of sub-models through effective notch stress analysis. In addition, the locations for evaluating the stress responses for the nominal stress approach were determined using these models. Fine meshes with element sizes of 1-3 mm were used in the region close to the $\mathrm{RD}$ joints. The steel deck and ribs around the joints were modeled using an element size of $10 \mathrm{~mm}$, whereas the other regions were modeled using an element size of $25 \mathrm{~mm}$.
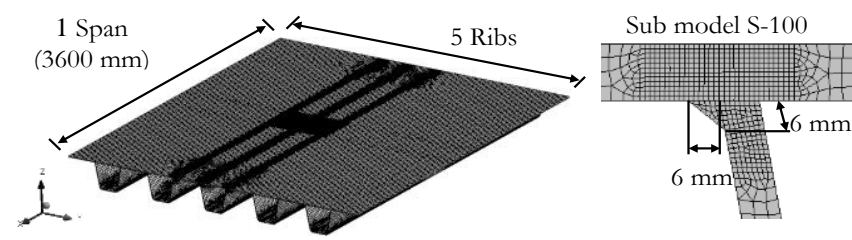

a) Sub-model S-100

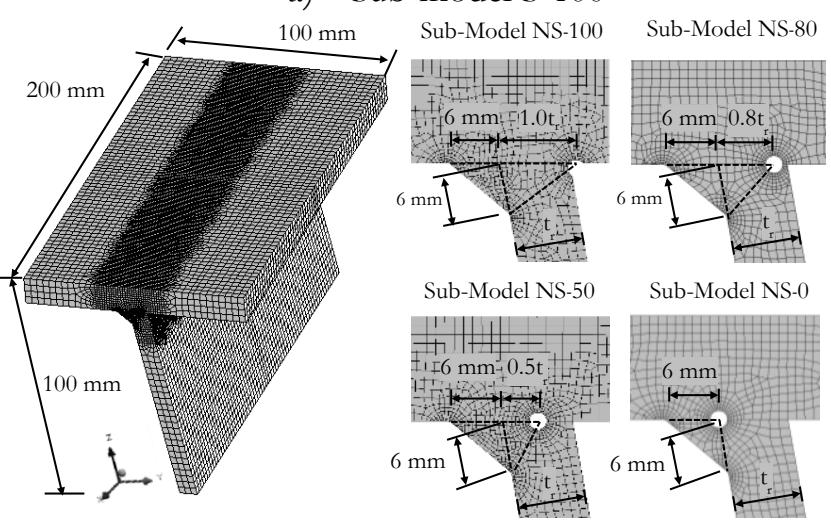

b) Sub-model NS

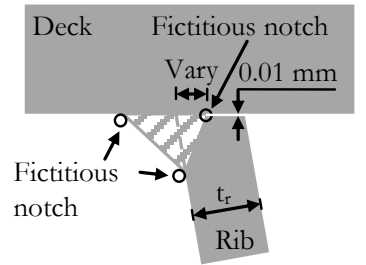

c) Fictitious notches at weld toe and root

Fig. 4. Sub-finite element models.

The small second level of sub-models with dimensions of $100 \mathrm{~mm} \times 200 \mathrm{~mm} \times 100 \mathrm{~mm}$ was developed to evaluate the notch stress responses. Submodels NS-0, NS-50, NS-80, and NS-100 (Fig. 4b) were applied to evaluate the stress responses at Joint A with 
$0 \%, 50 \%, 80 \%$, and $100 \%$ weld penetration ratios, respectively. The effect of the weld penetration ratio on the stress responses of the RD joint was evaluated using these models. Fictitious $1 \mathrm{~mm}$ radius notches, as recommended by the IIW [18], were used at the weld toes and weld root (Fig. 4c). A $0.01 \mathrm{~mm}$ root gap between the rib and deck was modelled [27,28]. An element size of $0.25 \mathrm{~mm}$ was used around the notches, according to IIW guidelines [18]. The boundary conditions of the NS models were constrained by the displacement of the large first level of the sub-models using the cut boundary condition method. The effective notch stresses at the weld toe and root were determined using von Mises stresses at the fictitious notches.

\subsection{Model Verification}

The finite element model based on the effective notch stress approach for evaluating fatigue crack type was verified using the fatigue test data obtained for an RD joint by Kainuma et al. [16]. A global finite element model was developed for Specimen D12U8SP50 used in their study (Fig. 5). The specimen had dimensions of $1400 \mathrm{~mm} \times 2000 \mathrm{~mm}$ with a $12 \mathrm{~mm}$ thick deck, $8 \mathrm{~mm}$ thick U-ribs, and $6 \mathrm{~mm}$ fillet weld for a $50 \%$ weld penetration ratio. The global model was developed using 20 -node solid elements with a quadratic displacement function (SOLID 186) (Fig. 5). The root gap between the rib and deck was $0.01 \mathrm{~mm}$. Figure 6 shows a comparison of the transverse strains along the longitudinal direction at $5 \mathrm{~mm}$ from the weld toe under $98 \mathrm{kN}$ single- and double-wheel loads obtained using the global finite element model and the experimental static-loading test data. The analytical strains were found to be in good agreement with the experimental static-loading test data.

A $100 \mathrm{~mm} \times 200 \mathrm{~mm} \times 100 \mathrm{~mm}$ sub-finite element model was developed to evaluate the notch stresses at the weld toe and root of each specimen (Fig. 7). The fictitious $1 \mathrm{~mm}$ radius notches were used at the weld toes and weld roots. The root gap between the rib and deck was $0.01 \mathrm{~mm}$. An element size of $0.25 \mathrm{~mm}$ around the notches was used. The boundary conditions of the subfinite element model were constrained by the displacement of the global finite element model using the cut boundary condition method. The effective notch stresses (von Mises stresses) under the fatigue test loading conditions that generated the maximum compressive stress at the joint (loading conditions of 218 $\mathrm{kN}$ front single wheel and $118 \mathrm{kN}$ midspan double wheel) and maximum tensile stress at the joint (unloading conditions of $218 \mathrm{kN}$ front single wheel and $11.8 \mathrm{kN}$ midspan double wheel) are depicted in Figs. 8(a) and 8(b), respectively. Relatively high effective notch stresses were obtained (Fig. 8(a)), which were expected to form fatigue cracks at the RD joints. For the analysis, the crack angles of the root-deck, toe-deck, and toe-rib were $108^{\circ}, 72^{\circ}$, and $24^{\circ}$, respectively. The analytical results were in good agreement with the experimental results for fatigue cracks at the root-deck and toe-deck having crack angles of $116.5^{\circ}$ and $85.1^{\circ}$, respectively.

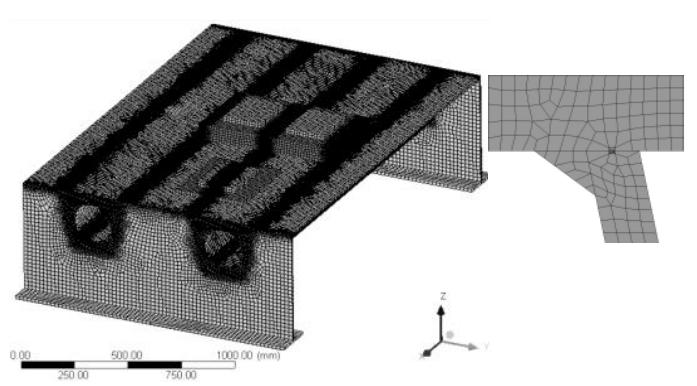

Fig. 5. Global finite element model for Specimen D12U8SP50 of Kainuma et al. [16].

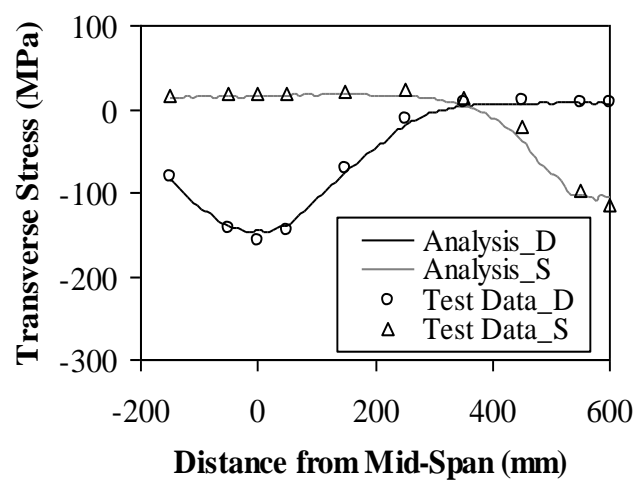

Fig. 6. Analytical strains and experimental data reported by Kainuma et al. [16].
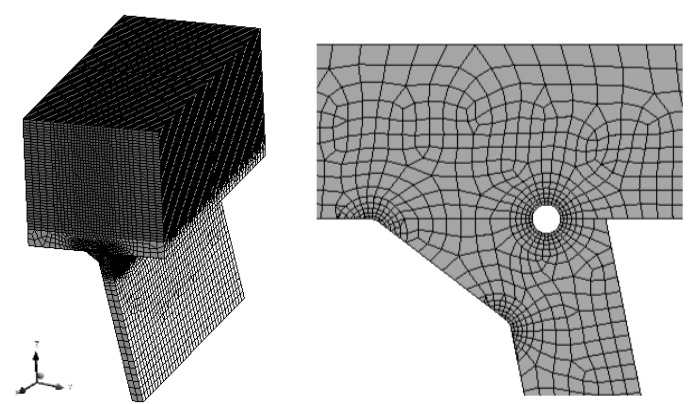

Fig. 7. Sub-finite element model for notch stress analysis of Specimen D12U8SP50 obtained by Kainuma et al. [16].



a) Loading condition

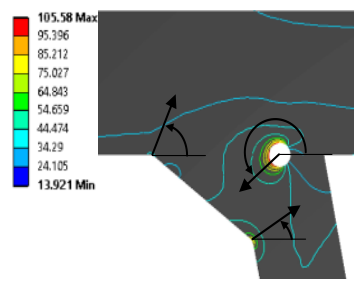

b) Unloading condition
Fig. 8. Effective notch stresses of Specimen D12U8SP50 obtained by Kainuma et al. [16]. 


\section{Critical Location of Transverse Wheel Loads}

\subsection{Deformation and Rotation}

The global finite element model was used to investigate the critical transverse locations of the wheel loads. The centers of the single- and double-wheel loads were transversely located (in the Y-direction) between -600 to $900 \mathrm{~mm}$ from the joints in increments of $50 \mathrm{~mm}$. These locations corresponded to cases in which the center of the wheel loads was located between and over the adjacent ribs.

Figure 9 shows the deformation and rotation for various transverse locations of $1 \mathrm{kN}$ single- and doublewheel loads. The single and double wheels are denoted as $\mathrm{S}$ and $\mathrm{D}$ in the figures. The deformation in the $\mathrm{Z}$ direction and rotation about the $\mathrm{X}$-axis were determined at the rib bottom, and the deformations in the $\mathrm{Z}$ direction under the single- and double-wheel loads were maximum at a transverse distance of $150 \mathrm{~mm}$. This distance corresponded to the location at which the center of the wheel loads was over the midspan between the rib walls. The maximum deformations under single- and double-wheel loads were 0.016 and $0.014 \mathrm{~mm}$, respectively.

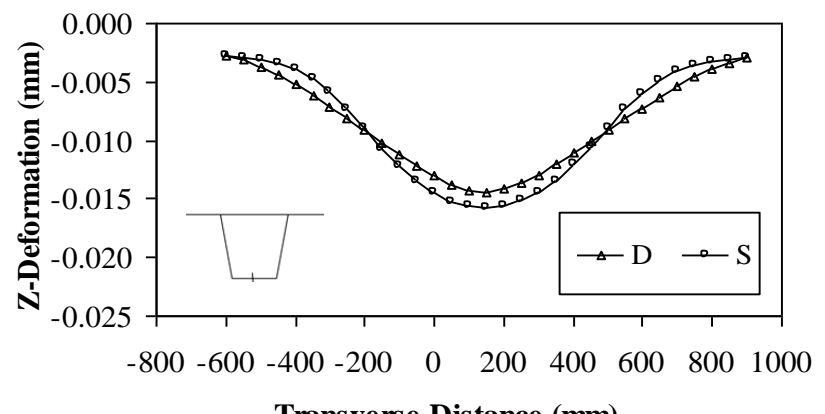

Transverse Distance (mm)

a) Z-deformation

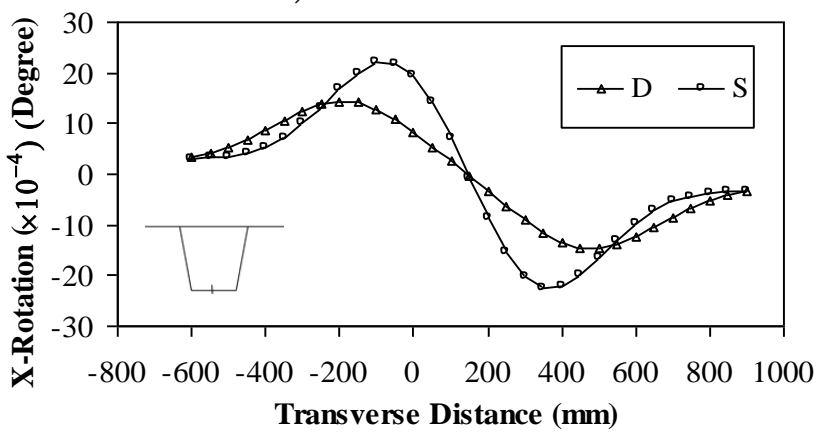

b) X-rotation

Fig. 9. Deformation and rotation of rib for different transverse wheel load locations.

The RD joint exhibited maximum rotations when the center of the wheel loads was located approximately between the two ribs. Maximum positive rotations that generated the tensile stress at the weld toe were obtained when the centers of the single and double wheels were located at -100 and $-200 \mathrm{~mm}$, respectively, from the joints. Similarly, the maximum negative rotations that produced the tensile stress at the weld root were generated when the centers of the single- and doublewheel loads were located at 350 and $500 \mathrm{~mm}$, respectively, from the joints.

\subsection{Internal Force and Nominal Stress}

The global model was applied to investigate the internal force and stress responses at Joint A using the nominal stress approach. The nominal stresses should be located away from the joints, where the stress responses are unaffected by the weld geometry (Fig. 10a). Figure $10 \mathrm{~b}$ shows the ratio of the transverse stresses obtained for the global model and sub-model S-100 at the center of the $1 \mathrm{kN}$ double-wheel load applied at Joint A. The variations in the stress ratios of toe-deck, root-deck, and toe-rib were determined at distances close to the joint because of the weld geometry. These stress ratios were relatively constant and approached a value of 1.0 at 18 , 12 , and $20 \mathrm{~mm}$ from the joint for toe-deck, root-deck, and toe-rib, respectively. In this study, the distances (Fig. 11) were used to evaluate the nominal stresses at the joint. It should be noted that the thicknesses of the deck and rib are denoted by $t_{d}$ and $t_{r}$ in Fig. 11. Previous studies $[2,8,9]$ evaluated the nominal stress at $5 \mathrm{~mm}$ away from the weld toe of RD joints. This location corresponded to distances of 15 and $17 \mathrm{~mm}$ from the RD joint to the deck and rib, respectively, and was relatively close to 18 and $20 \mathrm{~mm}$ obtained based on the stress ratio.

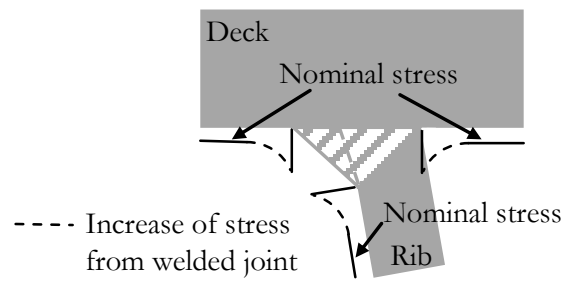

a) Nominal stress at RD joint

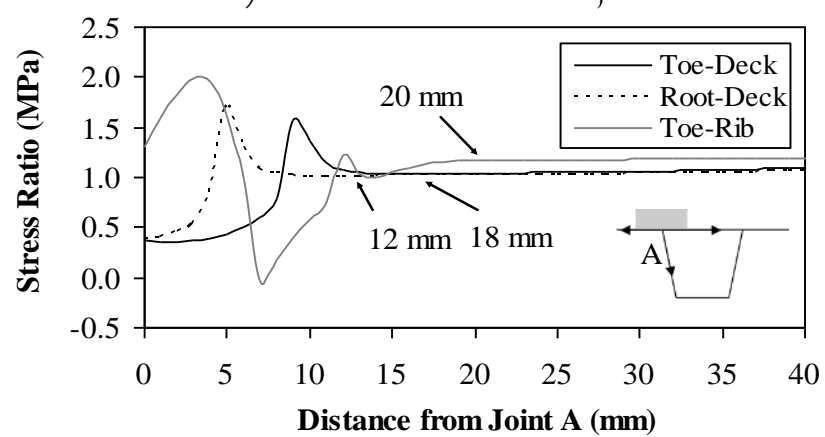

b) Transverse stress ratio between global model and submodel S-100

Fig. 10. Nominal stress and transverse stress ratio at RD joint. 


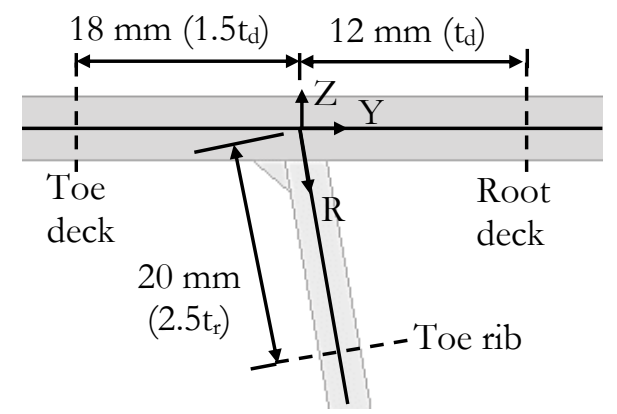

Figure 12 shows the bending moment and axial force at Joint A for various transverse locations of the singleand double-wheel loads. With respect to various wheel load locations, the bending moments at the toe-deck and root-deck were comparable. Moreover, relatively high axial forces were obtained at the toe-rib.

Fig. 11. Locations for evaluation of nominal stresses.

Table 1. Summary of critical transverse wheel load locations.

\begin{tabular}{|c|c|c|c|c|c|c|c|}
\hline \multirow{2}{*}{ Case } & \multirow{2}{*}{ Description } & \multicolumn{3}{|c|}{ Critical location } & \multicolumn{2}{|c|}{$\begin{array}{l}\text { Transverse location } \\
\qquad \text { (Y) (mm) }\end{array}$} & \multirow{2}{*}{$\begin{array}{l}\text { Deformation at } \\
\text { joint }\end{array}$} \\
\hline & & $\begin{array}{l}\text { Toe- } \\
\text { deck }\end{array}$ & $\begin{array}{l}\text { Root- } \\
\text { deck }\end{array}$ & $\begin{array}{l}\text { Toe- } \\
\text { rib }\end{array}$ & $\begin{array}{l}\text { Single } \\
\text { wheel }\end{array}$ & $\begin{array}{l}\text { Double } \\
\text { wheels }\end{array}$ & \\
\hline 1 & $\begin{array}{l}\text { Max. negative moment at deck and } \\
\text { max. compression force at rib wall }\end{array}$ & $\mathrm{X}$ & $\mathrm{X}$ & $\mathrm{X}$ & 0 & 0 & \\
\hline 2 & Max. negative moment at rib wall & - & - & $\mathrm{X}$ & -200 & -350 & \\
\hline 3 & Max. positive moment at rib wall & - & - & $\mathrm{X}$ & 200 & 350 & \\
\hline 4 & $\begin{array}{l}\text { Max. positive moment at deck and } \\
\text { max. tensile force at rib wall }\end{array}$ & $\mathrm{X}$ & $\mathrm{X}$ & $\mathrm{X}$ & 450 & 600 & \\
\hline 5 & Max. rotation of rib & - & - & $\mathrm{X}$ & -100 & -200 & \\
\hline 6 & $\begin{array}{l}\text { Max. panel deformation of rib } \\
\text { (loads on rib) }\end{array}$ & $\mathrm{X}$ & $\mathrm{X}$ & - & 150 & 150 & \\
\hline
\end{tabular}

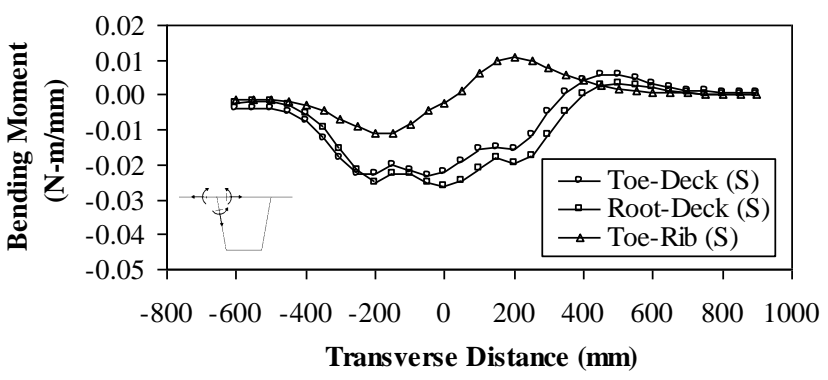

a) Bending moment under $1 \mathrm{kN}$ single-wheel load

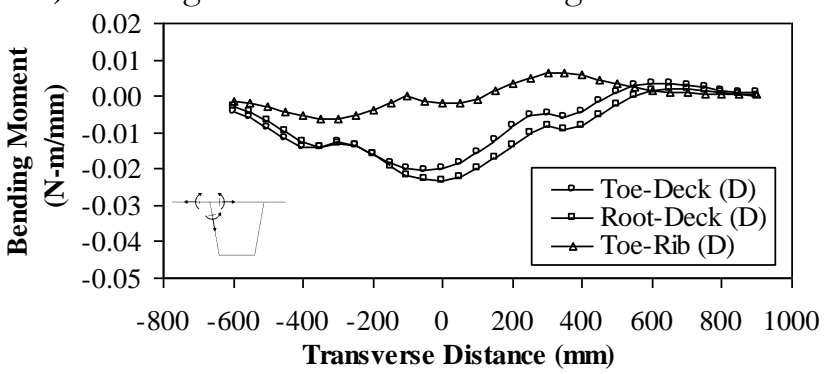

b) Bending moment under $1 \mathrm{kN}$ double-wheel loads

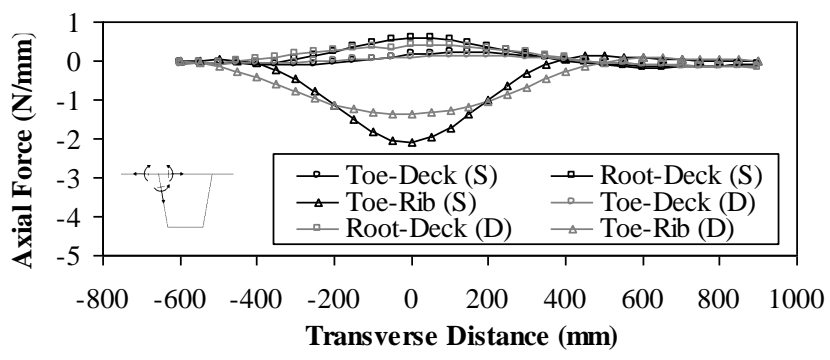

c) Axial force under $1 \mathrm{kN}$ single- and double-wheel loads

Fig. 12. Influence lines of internal forces under different transverse load locations at Joint A.

Six critical transverse wheel load locations were determined from the analysis. Maximum negative moments at the toe-deck and root-deck were observed when the centers of the single- and double-wheel loads were located at the RD joint or a transverse distance of $0 \mathrm{~mm}$ from the joint (Case 1). Furthermore, maximum positive moments at the toe-deck and root-deck were obtained when the centers of the single- and doublewheel loads were placed at transverse distances of 450 and $600 \mathrm{~mm}$, respectively, from the joint (Case 4). Maximum positive and negative bending moments at the toe-rib were obtained when the loading areas were close to the adjacent rib (Case 2) and close to the 
adjacent rib wall (Case 3). The magnitude of the axial forces at the toe-deck and root-deck were relatively low for various transverse wheel load positions. These low values indicated that bending moments dominated the internal force responses at the toe-deck and root-deck. The axial forces at the toe-rib were relatively high when the centers of the wheel loads were located at the RD joint (Case 1).

The critical locations of the single- and doublewheel loads that generated the maximum bending moment and axial force at the RD joint are shown in Table 1 and Fig. 13. Cases 5 and 6 corresponded to the wheel load locations that induced the maximum rotation and maximum panel deformation of the rib, respectively.

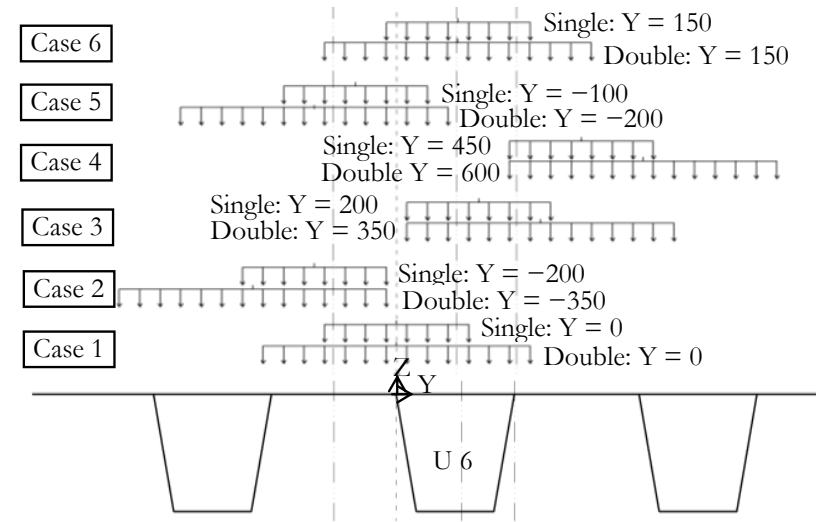

Fig. 13. Critical transverse wheel load locations (Dimensions in $\mathrm{mm}$ ).

Figure 14 shows the total nominal transverse stresses at Joint A, as obtained from the flexural and membrane stresses at the toe-deck, root-deck, and toerib for various transverse wheel load locations. The stresses at the joint were significant only when the wheel was close to the joint, which indicated that the stress range influenced by nearby axles or side-by-side vehicles did not significantly affect the stress range at the RD joints. The stress-sensitive regions of the travel paths for the single- and double-wheel loads were within the transverse distance range of $\pm 600 \mathrm{~mm}$ from the joints.

The maximum magnitude stresses at the toe-deck and root-deck were controlled by the flexural stresses and obtained for Case 1, which generated the maximum bending moment in the deck plate. The wheel load locations dominated the maximum magnitude stresses at the toe-rib in Cases 2 and 3; the magnitudes of the stresses obtained for these cases exceeded the value obtained for the case with the maximum axial force (Case 1). This result indicates that the membrane stress at the toe-rib was insignificant when compared to the flexural stress, despite the high axial force in Case 1.

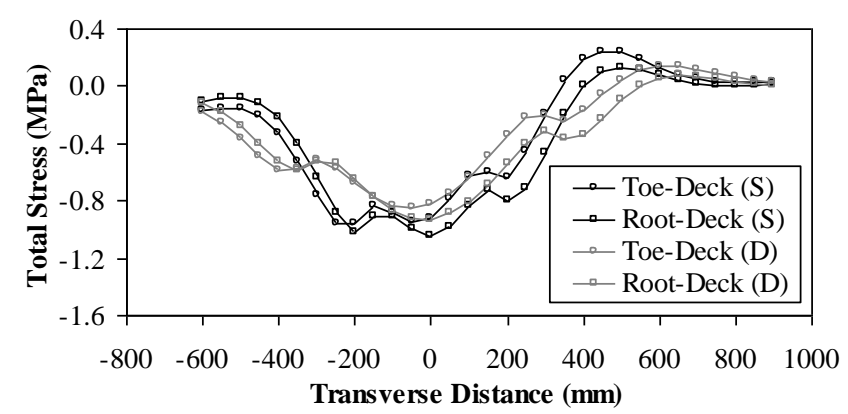

a) Stress at weld toe and root of deck

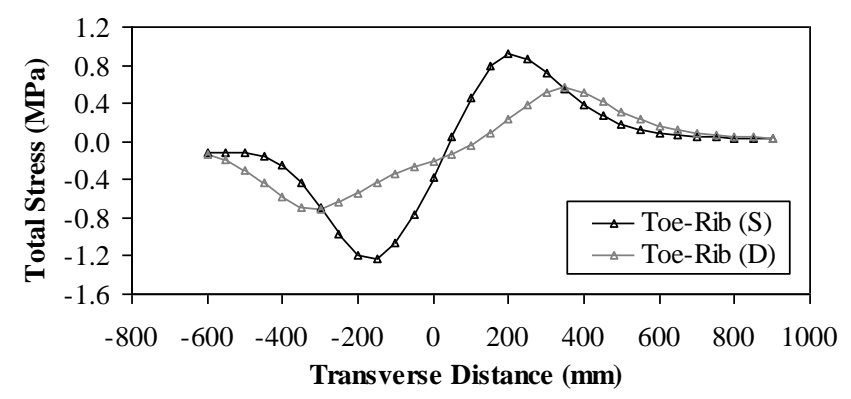

b) Stress at weld toe of rib

Fig. 14. Transverse influence line of transverse stresses at Joint $A$.

\section{Nominal Stress Range and Critical Wheel Load Location}

The longitudinal influence lines of transverse stresses at Joint A were determined for the six critical travel paths listed in Table 1 . In the global model, the 1 $\mathrm{kN}$ single- and double-wheel loads were applied in the longitudinal direction at incremental steps of $50 \mathrm{~mm}$ for locations within $\pm 1000 \mathrm{~mm}$ from the joint and $600 \mathrm{~mm}$ for locations at a longer distance from the joint. An analysis was performed for an array of $75 \times 6$ simulations.

Figure 15 shows the distinct influence lines of the transverse stresses at the toe-deck, root-deck, and toerib when $1 \mathrm{kN}$ double-wheel loads moved along the orthotropic deck in the longitudinal directions corresponding to Cases 1, 2, and 3. When the wheel load was applied at the joint, peak stress in either compression or tension was obtained at fatigue-sensitive locations of the joint. As shown in Fig. 15, peak compressive stresses were determined at the fatiguesensitive locations for Cases 1 and 2 when the longitudinal distance from the joint was zero. At the longitudinal distance, Case 3 exhibited the maximum tensile stress at the toe-rib.

For Case 1, the maximum tensile stresses at the toedeck, root-deck, and toe-rib were obtained when the wheel load was located at $500 \mathrm{~mm}$ from the joint. The maximum tensile stresses with relatively low magnitudes were obtained for Case 2 when the wheel load was applied to the adjacent span. In all the six cases, peak stresses with significant magnitudes were determined when the wheel loads were located at longitudinal 
distances within the range of $\pm 500 \mathrm{~mm}$ away from Joint A.



a) Case 1

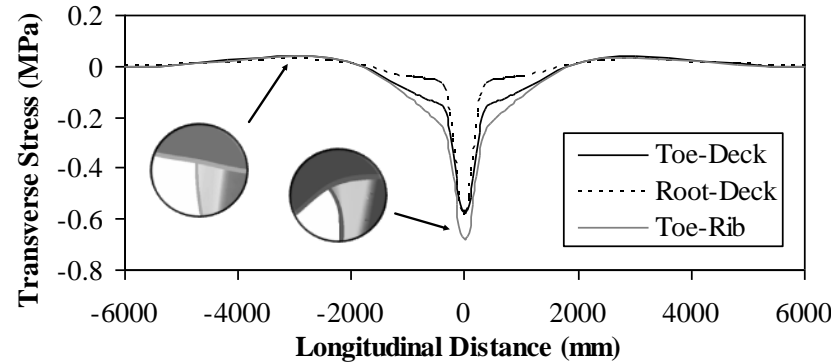

b) Case 2

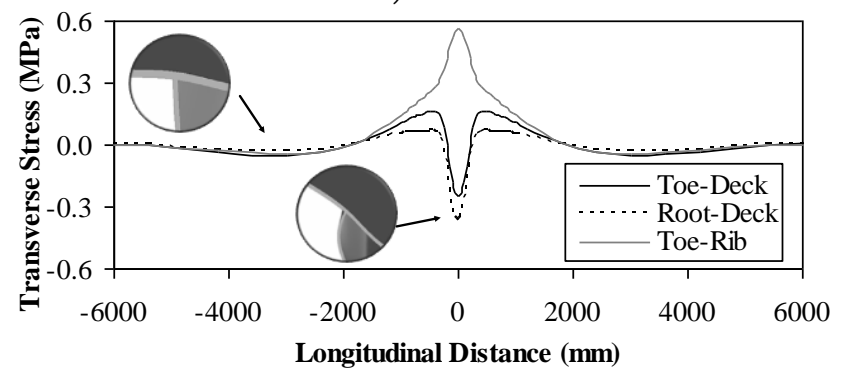

c) Case 3

Fig. 15. Longitudinal influence lines of transverse stresses at Joint $\mathrm{A}$ under $1 \mathrm{kN}$ double-wheel loads.

Figure 16 shows the stress range and tensile stress at Joint $\mathrm{A}$ for different transverse locations of $1 \mathrm{kN}$ single- and double-wheel loads. Higher magnitudes of stress responses were obtained for the single-wheel load than the double-wheel load, owing to a smaller tire contact area. The fatigue damage was more related to the stress range than the maximum tensile stress because of the existence of residual tensile stresses at the weld joint [4]. The maximum stress ranges at the toe-deck and root-deck were obtained for Case 1 when the travel path of the wheel loads was above the rib wall. The maximum stresses at the toe-deck, root-deck, and toe-rib for this loading case were $1.24,1.42$, and 0.41 $\mathrm{MPa}$, respectively for the single-wheel load, and 0.98 , 1.10 , and $0.24 \mathrm{MPa}$ for the double-wheel load. These stress values indicated that the root-deck was more susceptible to fatigue damage than the toe-deck and toerib considering the heavy double-wheel loads applied over the rib wall. For Case 2 (wheel loads on the adjacent rib), the stress ranges at the toe-rib exceeded those at the toe-deck and root-deck, which signified that fatigue cracking was likely to originate from the toe-rib. The maximum stress ranges at the toe-rib for Case 2 were 1.21 and $0.72 \mathrm{MPa}$ for the single- and doublewheel loads, respectively.
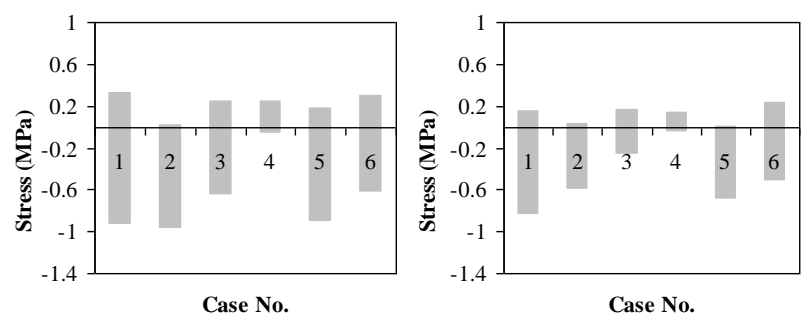

a) Toe-deck single-wheel

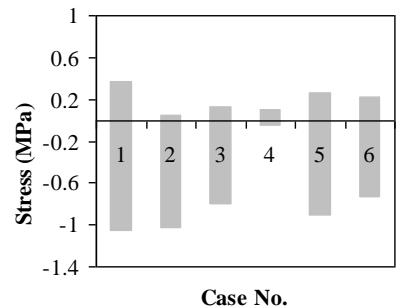

b) Toe-deck double-wheel

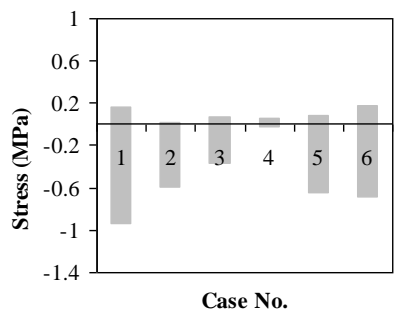

c) Root-deck single-wheel d) Root-deck double-wheel
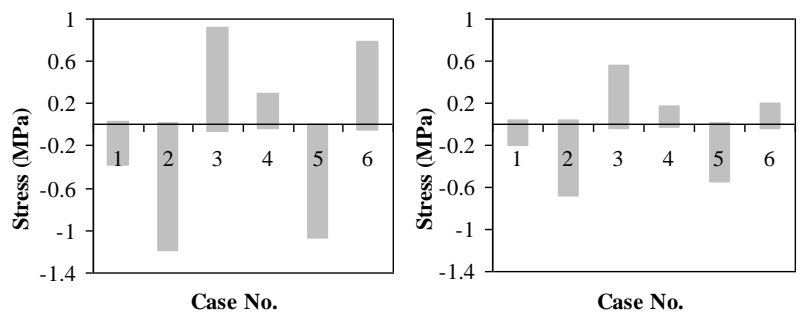

e) Toe-rib single-wheel f) Toe-rib double-wheel Fig. 16. Stress range at Joint A under $1 \mathrm{kN}$ single- and double-wheel loads.

After the formation of cracks, the effect of the tensile stress on crack propagation was more significant, owing to the release of residual stress at the crack tip [13]. The maximum tensile stress increased as the distance between the centers of the wheel loads became closer to the adjacent rib wall (Fig. 17). For Case 6, the maximum tensile stresses at the toe-deck and root-deck under the double-wheel loads were determined. However, the maximum tensile stresses at the toe-deck and root-deck under the single-wheel load for Case 1 were slightly higher than those of the double-wheel loads for Case 6. Relatively high tensile stresses were obtained at the toe-rib under the single- and doublewheel loads for Case 3. Therefore, the transverse wheel load locations corresponding to Cases 1, 3, and 6 had a more critical effect on fatigue crack propagation than those in other cases. 


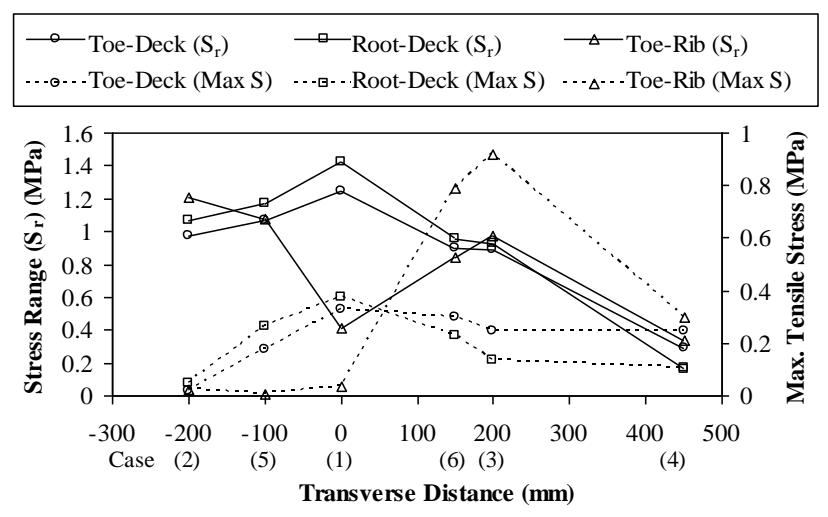

a) $1 \mathrm{kN}$ single-wheel load

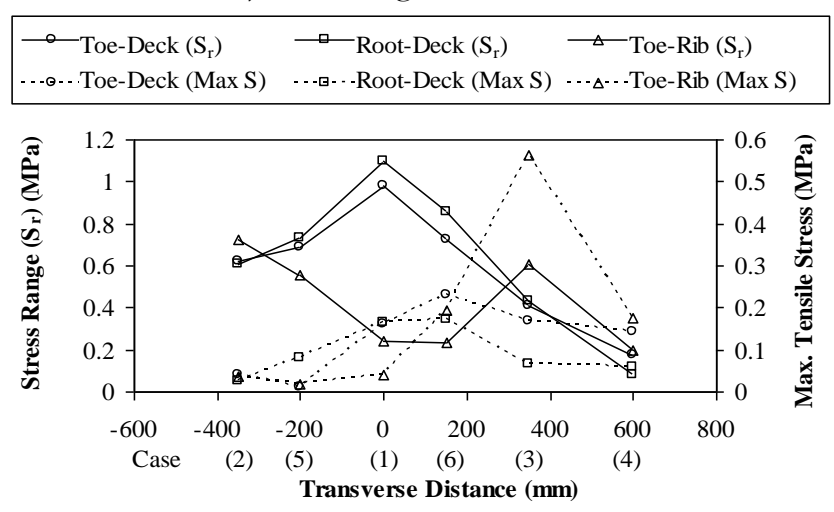

b) $1 \mathrm{kN}$ double-wheel load

Fig. 17. Stress range and tensile stress at Joint A for different wheel load locations.

\section{Fatigue Crack Type}

The effective notch stress approach was applied to evaluate the fatigue crack type for different transverse positions of $17.8 \mathrm{kN}$ single-wheel and $35.57 \mathrm{kN}$ doublewheel loads, which corresponded to the wheel loads of the AASHTO fatigue truck (Fig. 18). Figure 19 depicts the effective notch stresses of the RD joint for $0 \%, 50 \%$, $80 \%$, and $100 \%$ weld penetration ratios when the 35.57 $\mathrm{kN}$ double-wheel load was applied at the RD joint (Case 1). For the $0 \%$ weld penetration ratio, the relatively high effective notch stresses existed at weld root on the upper and lower sides of the notch hole. Therefore, fatigue cracks originated at the weld root and subsequently propagated into the deck or weld throat. For the other weld penetration ratios, the maximum effective notch stress was generated at the weld root on the upper side of the notch hole with a relatively low effective notch stress on the lower side of the notch hole. For these weld penetration ratios in Case 1, fatigue cracks were formed at the weld root and propagated into the deck. Furthermore, the maximum effective notch stress at the weld root decreased with an increase in the weld penetration ratio. The analytical results suggested that for Case 1, an increase in the weld penetration ratio could prevent weld root cracking and increase the fatigue resistance of the RD joint. Similar results were obtained in the experimental study conducted by Li et al. [9].



Fig. 18. AASHTO fatigue truck for orthotropic deck (Dimensions in $\mathrm{mm}$ ).

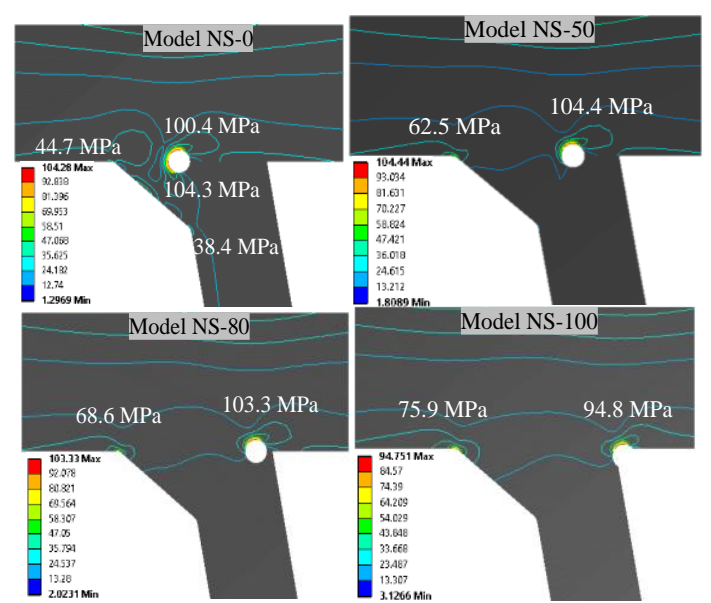

Fig. 19. Effective notch stress at rib deck joint for Case 1.

The effects of the weld penetration ratio and load case on the effective notch stress at fatigue-sensitive locations under $17.8 \mathrm{kN}$ single-wheel and $35.57 \mathrm{kN}$ double-wheel loads were analyzed (Fig. 20). The results indicated that the effect of the weld penetration ratio on the magnitude of the effective notch stress significantly depended on the transverse wheel load location. In addition, for most of the loading cases, the effects of the weld penetration ratio on the effective notch stress for the single- and double-wheel loads were similar. An increase in the weld penetration ratio significantly increased the toe-deck notch stress when the single- and double-wheel loads were positioned at the RD joint (Case 1) and close to the adjacent rib (Cases 2 and 5). For Cases 3 and 4, the weld penetration ratio had an insignificant effect on the toe-deck notch stress when the wheel loads were close to the adjacent rib wall. For the notch stress at the weld root, an increase in the weld penetration ratio gradually decreased the notch stress for most loading cases. When the loads were over the rib (Case 6) and close to the adjacent rib wall (Case 3), the notch stress at the weld root significantly decreased with an increase in the weld penetration ratio. This trend signified that an increase in the weld penetration ratio improved the fatigue resistance of the rib directly subjected to truck wheel loads. Compared to the notch stresses at the toe-deck and weld root, the notch stress at the toe-rib had a relatively low magnitude, which indicated less susceptibility to fatigue crack occurrence at this location. An increase in the weld penetration ratio from $0 \%$ to $50 \%$ decreased the effective notch stress at the toe-rib under the single-wheel load for 
Cases 1 and 5 and under the double-wheel load for Cases 1, 5, and 6. With an increase in the weld penetration ratio from $50 \%$ to $100 \%$, all the loading cases showed a similar trend in decreasing the notch stress at the toe-rib.
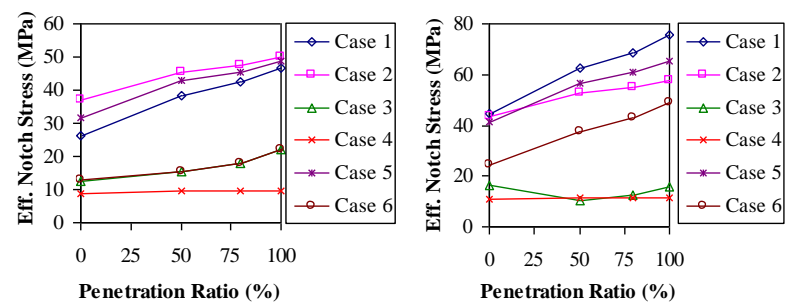

a) Toe-deck single-wheel

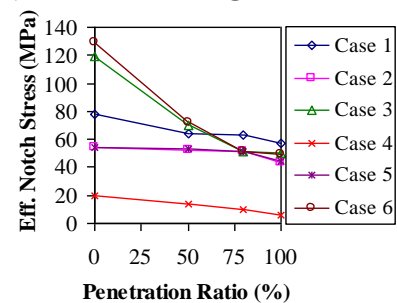

b) Toe-deck double-wheel

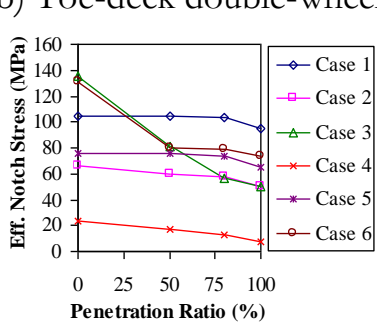

c) Weld root single-wheel

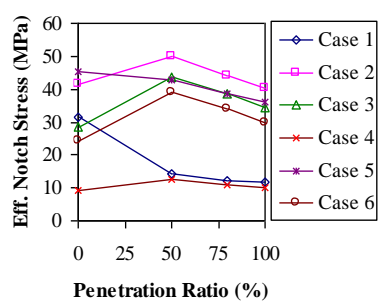

d) Weld root double-wheel

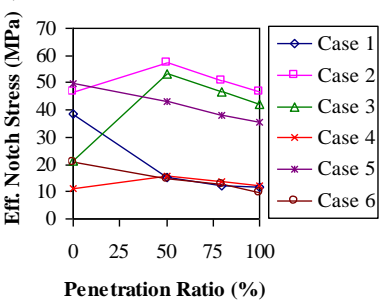

e) Toe-rib single-wheel f) Toe-rib double-wheel

Fig. 20. Effective notch stresses for different weld penetration ratios and load cases.

The fatigue crack types for different weld penetration ratios and load cases under the single- and double-wheel loads were evaluated (Fig. 21). The critical crack types were determined for the maximum effective notch stress and its corresponding location on the notch hole, and for most of the weld penetration ratios and load cases, the single- and double-wheel loads induced similar fatigue cracks. Except for the 50\% weld penetration ratio in Case 6 and $80 \%$ weld penetration ratio in Case 3, the single- and double-wheel loads generated different fatigue crack types. In Fig. 21, the fatigue crack types corresponding to Cases 6 and 3 under the single-wheel load are denoted as $6^{*}$ and $3^{*}$, respectively, while those under the double-wheel loads are denoted as $\underline{6}$ and $\underline{3}$, respectively. The analytical results showed that the critical location for fatigue crack initiation was influenced by the weld penetration ratio and transverse wheel load location. For the $0 \%$ weld penetration ratio, fatigue cracks originated at the weld root and propagated into the weld throat in most loading cases. As the weld penetration ratio increased to $80 \%$, fatigue cracks tended to be formed at the weld root and propagate into the deck. Cracking occurred at the toe-deck and toe-rib for a 100\% weld penetration ratio in Cases 2, 4, and 5.
For Case 2 (wheel loads on the adjacent rib), the fatigue crack types were the weld root crack for the $0 \%$ weld penetration ratio, root-deck crack for $50 \%$ and $80 \%$ penetration ratios, and toe-deck crack for the $100 \%$ weld penetration ratio. The fatigue cracks shifted from the weld root to the weld toe with an increase in the weld penetration ratio. In addition, the nominal stress approach yielded the fatigue crack type of toe-rib for this loading condition. Owing to the limitation of the nominal stress approach in which the weld geometry effect on the stress response is ignored, the effect of the weld penetration ratio on the fatigue crack could not be incorporated in the analysis. Hence, an inaccurate fatigue crack type was obtained for this loading case using the nominal stress approach. For Case 1 (the load acting at the RD joint), the effective notch stress produced a fatigue crack type of the root-deck crack for weld penetration ratios of $50 \%, 80 \%$, and $100 \%$, which was similar to the nominal stress approach. In addition, a similar fatigue crack type of root-deck crack was obtained from the two approaches for weld penetration ratios of $80 \%$ and $100 \%$, when the wheel loads were applied over the rib (Case 6). For Case 3 (the load positioned close to the adjacent rib wall), the effective notch stress approach provided the critical fatigue crack location at the weld root for all the weld penetration ratios. However, the nominal stress approach provided the critical fatigue crack type at the toe-rib. Therefore, the nominal stress approach could not be used to provide an accurate fatigue crack type for Case 3.

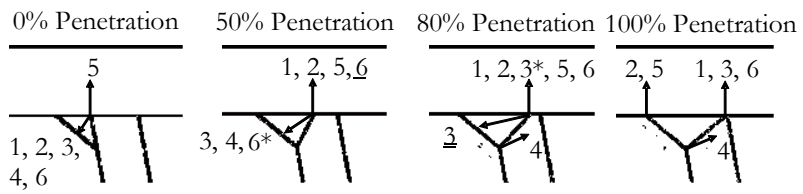

Fig. 21. Fatigue crack type.

\section{Comparison of Fatigue Life}

The fatigue lives for different loading cases and weld penetration ratios were evaluated using the nominal and effective notch stress approaches. The 17.8 $\mathrm{kN}$ single-wheel and $35.57 \mathrm{kN}$ double-wheel loads of the AASHTO fatigue truck were used in the calculation. The nominal stress ranges were determined through nominal stress analysis under $1 \mathrm{kN}$ single- and doublewheel loads (Fig. 17). The effective notch stress range and equivalent stress (von Mises stress) were calculated using the following equation [29]:

$$
\Delta \sigma_{\mathrm{e}}=\left[\left(\Delta \sigma_{z}\right)^{2}+\left(\Delta \sigma_{\mathrm{y}}\right)^{2}-\left(\Delta \sigma_{z}\right)\left(\Delta \sigma_{\mathrm{y}}\right)+3\left(\Delta \tau_{z \mathrm{y}}\right)^{2}\right]^{1 / 2}
$$

where $\Delta \sigma_{z}$ and $\Delta \sigma_{y}$ are the normal stress ranges perpendicular and parallel to the weld joint, respectively, and $\Delta \tau_{\mathrm{xy}}$ is the shear stress range parallel to the weld joint. 
Figure 22 depicts the nominal and effective notch stress ranges for weld penetration ratios of $0 \%, 50 \%$, $80 \%$, and $100 \%$. For most loading cases and weld penetration ratios, the effective notch stress range exceeded the nominal stress range. This trend was attributed to the effect of the stress concentration from the weld profile and notch hole on the stress responses using the effective notch stress approach. For weld penetration ratios equal to or higher than $50 \%$, Case 1 (the load acting at the RD joint) showed higher nominal and effective notch stress ranges than those of other loading cases for both the single- and double-wheel loads. The nominal and effective notch stress approaches yielded the same critical transverse wheel load location for these weld penetration ratios. However, a variation in the critical transverse wheel load location was observed for the $0 \%$ weld penetration ratio using both approaches. Critical loading cases for the $0 \%$ weld penetration ratio under the single- and double-wheel loads were Cases 3 (the load over the adjacent wall) and 1 (the load at the RD joint), respectively, based on the effective notch stress approach. However, the nominal stress approach indicated that Case 1 was the critical loading case for both single- and double-wheel loads.

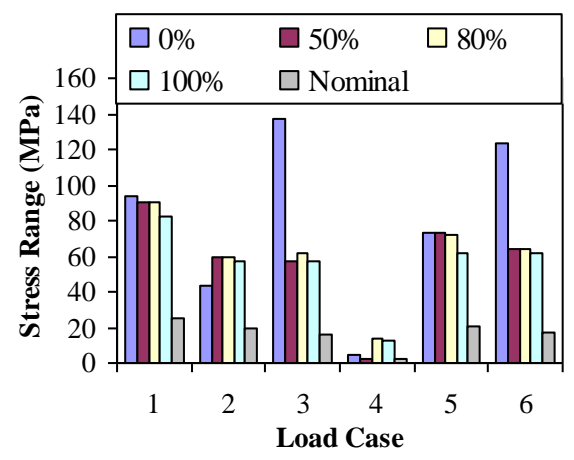

a) $17.8 \mathrm{kN}$ single-wheel

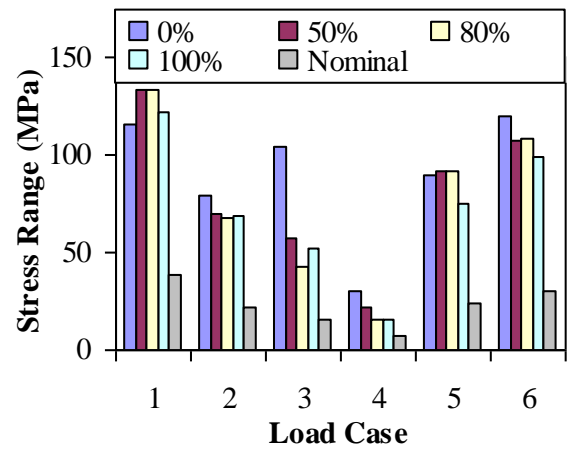

b) $35.57 \mathrm{kN}$ double-wheel

Fig. 22. Nominal and effective notch stress ranges for different transverse wheel load locations.

The fatigue lives per passage of $17.8 \mathrm{kN}$ singlewheel and $35.57 \mathrm{kN}$ double-wheel loads were computed using the effective notch and nominal stress approaches. The approaches were shown to provide the reasonable estimates of the total and initiation fatigue lives of the RD joint, respectively [17]. For the effective notch stress approach, the fatigue class FAT 200 was used to determine the fatigue life at the weld root and toe. The fatigue class was recommended by the IIW [18] for the fatigue life evaluation based on the effective notch stress (von Mises stress) determined from fictitious notches at weld toe and root and applicable for all weld penetration ratios. However, the fatigue class FAT 71 was used for the nominal stress approach, as recommended by the IIW [12]. The fatigue class was applied in calculating the fatigue life at the weld root and toe for the $100 \%$ weld penetration ratio and the weld throat for $0 \%$ and partial weld penetration ratios. An extension of the S-N line approach was adopted in the calculation, in which all the stress range levels under a variable amplitude loading contributed to the fatigue damage.

The fatigue lives for different transverse wheel load locations and weld penetration ratios based on the two approaches were compared (Fig. 23). The Case 4 fatigue life was omitted owing to its relatively low-stress ranges and slight fatigue damage. The analytical results indicated that the weld penetration ratio influenced the fatigue life provided by the effective notch stress approach. For most transverse wheel load locations, an increase in the weld penetration ratio increased the fatigue life. A reduction in the fatigue life with an increase in the weld penetration ratio was observed for some loading cases (e.g., an increase in the weld penetration ratio from $0 \%$ to $50 \%$ under a single-wheel load for Case 2 and double-wheel loads for Case 1). For these loading cases, the fatigue crack type changed with an increase in the weld penetration ratio.

When the weld penetration ratio increased from $0 \%$ to $50 \%$, a significant increase in the fatigue life occurred under a single-wheel load for Cases 3 (the load close to the adjacent wall) and 6 (the load over the rib) and under double-wheel loads for Case 3. Additionally, the fatigue life corresponding to the nominal stress range was more extended than the fatigue life obtained using the effective notch stress approach for all the loading cases with $100 \%$ weld penetration ratio. For this weld penetration ratio, the fatigue life values of the effective notch stress approach for all the loading cases ranged within $47 \%-66 \%$ and $59 \%-75 \%$ of that of the nominal stress approach under the single- and double-wheel loads, respectively. Additionally, for the critical load case (Case 1), the percentages of the fatigue life of the effective notch stress approach compared with the nominal fatigue life were $66 \%$ and $73 \%$ for the singleand double-wheel loads, respectively. 




a) $17.8 \mathrm{kN}$ single-wheel

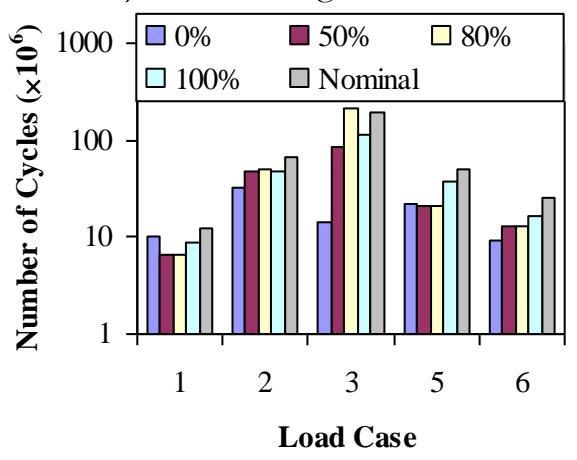

b) $35.57 \mathrm{kN}$ double-wheel

Fig. 23. Fatigue lives based on nominal and effective notch stress approaches.

\section{Conclusion}

In this study, finite element analysis was performed to evaluate the nominal and effective notch stress responses of the $\mathrm{RD}$ joint at the midspan of an orthotropic steel deck. Based on the analytical results, the following conclusions are drawn.

1. The wheel load location and configuration influenced the stress responses at the RD joint. The stress ranges and tensile stresses at the RD joint were dominated by flexural stress. Furthermore, significant magnitudes of the stress responses were obtained when the wheel loads were located at transverse and longitudinal distances of \pm 600 and $\pm 500 \mathrm{~mm}$ away from the joint, respectively.

2. The nominal and effective notch stress approaches yielded a similar critical transverse wheel load location for the RD joint for weld penetration ratios equal to or higher than $50 \%$. For these weld penetration ratios, the maximum nominal and effective notch stress ranges were obtained when the centers of the single- and double-wheel loads were positioned at the RD joint. The critical load location, however, varied for the joint with $0 \%$ weld penetration ratio using both approaches.

3. The effective notch stress approach could be used to predict the fatigue crack type of the RD joint effectively. For most weld penetration ratios and transverse loading locations, the nominal stress approach tended to provide inaccurate locations of fatigue crack initiation. A similar fatigue crack type was obtained for relatively high weld penetration ratios $(\geq$
$80 \%$ ) when the wheel loads were applied at the RD joint and over the rib using the nominal and effective notch stress approaches.

4. The stress responses at the $\mathrm{RD}$ joint were complex. The effective notch stresses at fatiguesensitive locations were influenced by the weld penetration ratio and transverse wheel load location. An increase in the weld penetration ratio decreased the root notch stress, which extended the fatigue life, particularly when the loads were applied over the rib and close to the adjacent wall. The toe-deck cracks increased with the weld penetration ratio when the loads were applied at the RD joint and close to the adjacent rib.

5. Despite the limitation of the fatigue resistance curve for the nominal stress approach, the effective notch stress approach facilitated the computation of the fatigue life at the weld root and toe for different weld penetration ratios. Based on a different concept of the fatigue life calculation, the variation in fatigue life was evaluated using the two approaches. For the 100\% weld penetration ratio with the loads applied at the RD joint, the fatigue life determined using the effective notch stress approach ranged from $66 \%$ to $73 \%$ of the nominal fatigue life.

\section{Acknowledgement}

The study was conducted with financial support of Kasetsart University Research and Development Institute (KURDI). The authors also acknowledge the support and assistance provided by the Expressway Authority of Thailand and the Infrastructure Monitoring and Management System (IMMS) Company.

\section{References}

[1] A. Karlsson and C. Wesley, "Fatigue analysis for orthotropic steel deck bridges," Master's Thesis, Department of Civil and Environmental Engineering, Chalmers University of Technology, 2015.

[2] S. Ya, K. Yamada, and T. Ishikawa, "Fatigue evaluation of rib-to-deck welded joints of orthotropic steel bridge deck," J Bridge Eng, vol. 16, no. 4, pp. 492-499, 2011.

[3] US Department of Transportation, "Manual for design, construction, and maintenance of orthotropic steel deck bridges," US Department of Transportation, Federal Highway Administration, Publication no. FHWA-IF-12-027, USA, 2012.

[4] H. B. Sim, C. M. Uang, and C. Sikorsky, "Effects of fabrication procedures on fatigue resistance of welded joints in steel orthotropic decks," J Bridge Eng, vol. 14, no. 5, pp. 366-373, 2009.

[5] H. B. Sim and C. M. Uang, "Stress analyses and parametric study on full-scale fatigue tests of ribto-deck welded joints in steel orthotropic decks, $J$ Bridge Eng, vol. 17, no. 5, pp. 765-773, 2012. 
[6] J. Bohai, L. Rong, C. Ce, M. Hirofumi, and C. Xiongfei, "Evaluation on root-deck fatigue of orthotropic steel bridge deck," I Constr Steel Res, vol. 90, pp. 174-183, 2013.

[7] B. Cheng, X. Ye, X. Cao, D. D. Mbako, and Y. Cao, "Experimental study on fatigue failure of ribto-deck welded connections in orthotropic steel bridge decks," Int J Fatigue, vol. 103, pp. 157-167, 2017.

[8] Z. Fu, B. Ji, C. Zhang, and Q. Wang, "Fatigue performance of roof and u-rib weld of orthotropic steel bridge deck with different penetration rates," J Bridge Eng, vol. 22, no. 6, pp. 04017016, 2017.

[9] M. Li, Y. Suzuki, K. Hashimoto, and K. Sugiura, "Experimental study on fatigue resistance of ribto-deck joint in orthotropic steel bridge deck," J Bridge Eng, vol. 23, no. 2, pp. 04017128, 2018.

[10] American Association of State Highway and Transportation Officials (AASHTO), AASHTO LRFD Bridge Design Specifications, AASHTO, Washington, DC, 2017.

[11] J. W. Fisher and J. Barsom, "Evaluation of cracking in the rib-to-deck welds of the bronxwhitestone bridge," J Bridge Eng, vol. 21, no. 3, pp. 04015065, 2016.

[12] A. Hobbacher, Recommendations for Fatigue Design of Welded Joints and Components. International Institute of Welding, 2008.

[13] S. Kainuma, M. Yang, Y. S. Jeong, S. Inokuchi, A. Kawabata, and D. Uchida, "Experiment on fatigue behavior of rib-to-deck weld root in orthotropic steel decks," J Constr Steel Res, vol. 119, pp. 113-122, 2016.

[14] S. Kainuma, Y. Jeong, M. Yang, and S. Inokuchi, "Welding residual stress in roots between deck plate and u-rib in orthotropic steel decks," Measurement, vol. 92, pp. 475-482, 2016.

[15] C. Cui, Y. Bu, Y. Bao, Q. Zhang, and Z. Ye, "Strain energy-based fatigue life evaluation of deck-to-rib welded joints in OSD considering combined effects of stochastic traffic load and welded residual stress," J Bridge Eng, vol. 23, no. 2, pp. 04017127, 2018.

[16] S. Kainuma, M. Yang, Y. S. Jeong, S. Inokuchi, A. Kawabata, and D. Uchida, "Experimental investigation for structural parameter effects on fatigue behavior of rib-to-deck welded joints in orthotropic steel decks," Eng Fail Anal, vol. 79, pp. 520-537, 2017.

[17] Q. Wang, B. Ji, Z. Fu, and Z. Ye, "Evaluation of crack propagation and fatigue strength of rib-todeck welds based on effective notch stress method," Constr Build Mater, vol. 201, pp. 51-61, 2019.

[18] W. Fricke, IIW Recommendations for the Fatigue Assessment of Welded Structures by Notch Stress Analysis, International Institute of Welding, 2012.

[19] P. Luo, Q. Zhang, Y. Bao, and Y. Bu, "Fatigue performance of welded joint between thickenededge U-rib and deck in orthotropic deck," Eng Struct, vol. 181, pp. 699-710, 2019.

[20] R. C. Battista, M. S. Pfeil, and E. M. L. Carvalho, "Fatigue life estimates for a slender orthotropic steel deck," J Constr Steel Res, vol. 64, no. 1, pp. 134-143, 2008.

[21] S. T. Freitas, H. Kolstein, and F. Bijlaard, "Structural monitoring of a strengthened orthotropic steel bridge deck using strain data," Struct Health Monit, vol. 11, no. 5, pp. 558-576, 2012

[22] I. Farreras-Alcover, M. K. Chryssanthopoulos, and J. E. Andersen, "Data-based models for fatigue reliability of orthotropic steel bridge decks based on temperature, traffic, and strain monitoring," Int J Fatigue, vol. 95, pp. 104-119, 2017.

[23] Z. Zhu, T. Yuan, Z. Xiang, Y. Huang, E. Zhou, and X. Shao, "Behavior and fatigue performance of details in an orthotropic steel bridge with UHPC-deck plate composite system under inservice traffic flows," J Bridge Eng, vol. 23, no. 3, pp. $04017142,2018$.

[24] Z. G. Xiao, K. Yamada, S. Ya, and X. L. Zhao, "Stress analyses and fatigue evaluation of rib-todeck joints in steel orthotropic decks," Int J Fatigue, vol. 30, no. 8, pp. 1387-1397, 2008.

[25] X. Y. Zhou, M. Treacy, F. Schmidt, E. Brühwiler, F. Toutlemonde, and B. Jacob, "Effect on bridge load effects of vehicle transverse in-lane position: a case study," J Bridge Eng , vol. 20, no. 12, pp. 04015020 , 2015.

[26] British Standard, Steel, Concrete and Composite Bridges Part 10: Code of Practice for Fatigue, BS 5400-10, 1980.

[27] H. B. Sim, "Effective notch stress method for fatigue evaluation of welded joints in a steel bridge deck," IJR Int J Railw, vol. 5, no. 2, pp. 89-92, 2012.

[28] C. V. Dung, E. Sasaki, K. Tajima, and T. Suzuki, "Investigations on the effect of weld penetration on fatigue strength of rib-to-deck welded joints in orthotropic steel decks," Int J Steel Struct, vol. 15, no. 2, pp. 299-310, 2015.

[29] M. M. Pedersen, "Multiaxial fatigue assessment of welded joints using the notch stress approach," Int $J$ Fatigue, vol. 83, pp. 269-279, 2016.

Piya Chotickai, photograph and biography not available at the time of publication.

Thongsoi Srisawat, photograph and biography not available at the time of publication. 